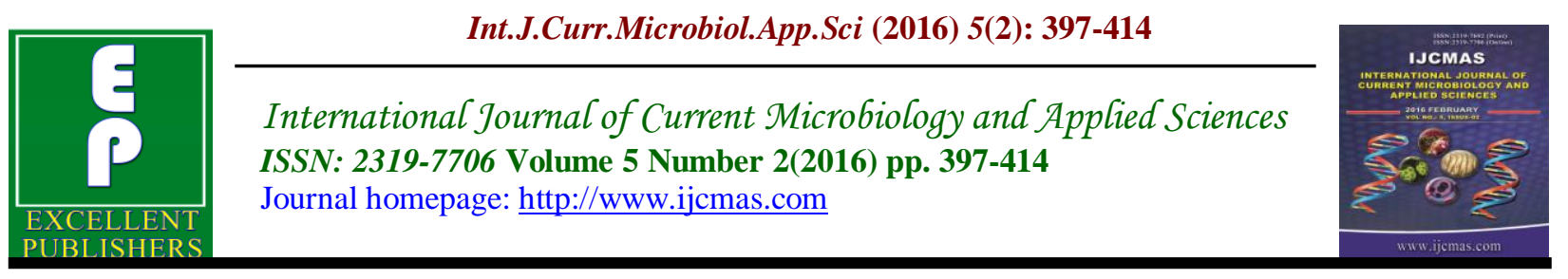

Review Article

doi: http://dx.doi.org/10.20546/ijcmas.2016.502.045

\title{
Nanomedicine Opened New Horizons for Metal Nanoparticles to Treat Multi-Drug Resistant Organisms
}

\author{
Eman Mohammed Halawani* \\ Medical Bacteriology, Biology department,science college, Taif University- Saudi Arabia \\ *Corresponding author
}

\begin{abstract}
A B S T R A C T
Keywords

Metal,

Antimicrobial, Multi-drug,

Resistance, Nanoparticles, biofilm

Article Info

Accepted:

20 January 2016

Available Online:

10, February 2016

Novel studies and technologies are devoted to understanding the mechanisms of disease for the design of new drugs, but unfortunately infectious diseases continue to be a major health burden world wide. Multi-drug resistance still growing problem in the treatment of infectious diseases, and the widespread use of broadspectrum antibiotics has produced antibiotic resistance for many human bacterial pathogens. Advances in nanotechnology have opened new horizons in nanomedicine, allowing the synthesis of nanoparticles that can be assembled into complex architectures. Since ancient times, metal was known for its anti-bacterial effects and for centuries it has been used for prevention and control of disparate infections. Currently nanotechnology and nanomaterials are fully integrated in common applications and objects that we use every day. In addition, the metal nanoparticles are attracting much interest because of their potent and wide spectrum antibacterial activity. Bacterial strains that are resistant to current antibiotics have become serious public health problems that increase the need to develop new bactericidal materials. Therefore, nanoparticles have gained importance in the field of biomedicine.
\end{abstract}

\section{Introduction}

Drug-resistant bacteria are emerging pathogens whose resistance profiles present a major hallenge for containing their spread and their impact on human healt $(1,6)$. Increasing hospital and community-acquired infections due to bacterial multidrugresistant (MDR) pathogens for which current antibiotic therapies are not effective represent a growing problem. Antimicrobial resistance is one of the major threats to human health (1), since it determines an increase of morbidity and mortality as a consequence of the most common bacterial diseases (2).Resistance genes have recently emerged favoured by improper use of antibiotics $(3$, 4)hence, the first step in combating resistance envisions the reduction of antibiotic consumption (5). Antimicrobial resistance is a complex mechanism whose etiology depends on the individual, the bacterial strains and resistance mechanisms that are developed (6). The emergence of resistance against newly developed antibiotics further supports the need for 
innovation, monitoring of antibiotic consumption, prevention, diagnosis and rapid reduction in the misuse of these drugs (7). It is necessary to optimize antibiotics' pharmacokinetics and pharmacodynamics in order to improve treatment outcomes and reduce the toxicity and the risk of developing resistance (8).

To address the problem of resistance, it will be necessary to change the protocols of use of antimicrobials so that these drugs are administered only when all other treatment options have failed (4), and joint efforts of governments and academic networks are needed to fight against the globally spreading of multidrug resistant pathogens. Today, there is aneed to seek alternative treatments (9). Non-traditional antibacterial agents are thus of great interest to overcome resistance that develops from several pathogenic microorganisms against most of the commonly used antibiotics (4). Nanotechnology offers unique approaches to control a wide variety of biological and medical processes that occur at nanometer length, and it is believed to have a successful impact on biology and medicine. $(8,9)$

\section{Nanoparticles and Multi-drug Resistance Organisms}

Nanoparticles are being viewed as elementary building blocks of nanotechnology, nanoparticles are now considered a viable alternative to antibiotics and seem to have a high potential to solve the problem of the emergence of bacterial multidrug resistance (10).In recent years, the use of nanoparticles, particularly metal nanoparticles has expanded in biomedical research. They are used in bioimaging, delivery, drug delivery and other diagnotic and therapeutics applications, due to their unique properties of small size, large surface area to volume ratio, high reactivity to the living cells, stability over high temperatures and translocation into the cells, etc $(9,11,13)$. Metal has always been used against various diseases; in the past it found use as an antiseptic and antimicrobial against Grampositive and Gram-negative bacteria $(14,16$, 22) due to its low cytotoxicity (17). Silver ions have been shown to interact with the thiol group in enzymes and in active them leading to cell death, they have also shown to interact with DNA to enhance pyrimidine dimerization by the photodynamic reaction and possibly prevent DNA replication. Elevated levels of metals ions inside a cell cause oxidative stress and the generation of hydrogen peroxide, causing oxidative damage to cells, decline in the membrane integrity of microbes, leading to leakage of specific essential cell nutrients, this leads to desiccation and subsequent cell death. Also nanoparticles can bind to protin, and this binding leads to loss-of-function of the protein, and/or breakdown of the protein into nonfunctional portions $(19,86)$.NPs were considered, in recent years, particularly attractive for the production of a new class of antimicrobials $(4,18,25)$ opening up a completely new way to combat a wide range of bacterial pathogens. Although the highly antibacterial effect of NPs has been widely described, their mechanism of action is yet to be fully elucidated. In fact, the potent antibacterial and broad-spectrum activity against morphologically and metabolically different microorganisms seems to be correlated with multifaceted mechanism by which nanoparticles interact with microbes (8).Moreover, their particular structure and the different modes of establishing an interaction with bacterial surfaces may offer a unique and under probed antibacterial mechanism to exploit.

From a structural point of view, NPs have at least one dimension in different size and 
shapes range from 1 to $100 \mathrm{~nm}$ and more importantly, as particle size decreases, the surface area-to-volume ratio greatly increases. $(22,35)$ As a consequence, the physical, chemical and biological properties are markedly different from those of the bulk material of origin. Several mechanisms of action of NPs and antibiofilms activities have been proposed by different authors, and the most corroborated are described below $(4,19)$.

\section{Drug Mechanisms of Action on Bacteria}

The treatment of bacterial infections is increasingly complicated by the ability of bacteria to develop resistance to antimicrobial agents. Antimicrobial agents are often categorized according to their principal mechanism of action. Mechanisms include interference with cell wall synthesis (eg, beta-lactams and glycopeptide agents), inhibition of protein synthesis (macrolides and tetracyclines), interference with nucleic acid synthesis (fluoroquinolones and rifampin), inhibition of ametabolic pathway (trimethoprim. sulfamethoxazole) and disruption of bacterial membrane structure (polymyxins and daptomycin)(3,8). Almost as soon as antibacterial drugs were deployed, bacteria respond by manifesting various forms of resistance. As antimicrobial usage increase, so did the level and of resistance mechanisms exhibited by bacterial pathogens, bacteria may manifest resistance to antibacterial drugs through a variety of mechanisms (8). Some species such as Acinetobacter baumannii becomes resistant to antibiotics by alteration of cell wall and cytoplasm. (26, 27) Escherichia coli Alteration of membrane permeability and respiration $(26,2,44)$ Enterococcus faecalis Alteration of cell wall and cytoplasm $\quad(42,45,46) . \quad$ Klebsiella pneumoniae Alteration of membrane (28,41,47), Listeria monocytogenes
Morphological changes, separation of the cytoplasmic membrane from the cell wall, plasmolysis (47), Micrococcus luteus Alteration of membrane (28), Nitrifying bacteria inhibits respiratory activity (31), Pseudomonas aeruginosa Irreversible damage on bacterial cells; Alteration of membrane permeability and respiration (17,36,48,50), Proteus mirabilis Alteration of cell wall and cytoplasm. (43) Staphylococcus aureus Irreversible damage on bacterial cells $(31,37,39,41)$. Staphylococcus epidermidis Inhibition of bacterial DNA replication, bacterial cytoplasm membranes damage, modification of intracellular ATP levels $(36,52)$ Salmonella typhi Inhibition of bacterial DNA replication, bacterial cytoplasm membranes damage and modification of intracellular ATP levels $(48,51)$ and Vibrio cholerae Alteration of membrane permeability and respiration (33).

NPs are able to physically interact with the cell surface of various bacteria, this is particularly important in the case of Gramnegative bacteria where numerous studies have observed the adhesion and accumulation of NPs to the bacterial surface. Many studies have reported that NPs can damage cell membranes leading to structural changes, which render bacteria more permeable $(14,53)$. This effect is highly influenced by the nanoparticles' size, shape and concentration $(53,56)$ and a study using Escherichia coli confirmed that NPs accumulation on the membrane cell creates gaps in the integrity of the bilayer which predisposes it to a permeability increase and finally bacterial cell death $(14,19)$. Several studies have shown that AgNP activity is strongly dependent on the size $(46,47)$. Infact, the bactericidal activity of NPs of smaller dimensions $(<30 \mathrm{~nm})$ was found to be optimal against Staphylococcus aureus and Klebsiella pneumoniae (49). Smaller 
nanoparticles seem to have a superior ability to penetrate into bacteria. In fact, the interactions with the membranes and any resulting damage, which may lead to cell death, are certainly more evident in the case of nanoparticles with smaller diameter and a positive zeta potential. Electrostatic forces that develop when nanoparticles with a positive zeta potential encounter bacteria with a negative surface charge promote a closer attraction and interaction between the two entities and possibly the penetration in bacterial membranes(32). Indeed, the zeta potential along with the size of the nanoparticles is a fundamental parameter for controlling the antimicrobial activity and more effective nanoparticles have a positive zeta potential and a reduced size. As said earlier, NPs have a surface/volume ratio much greater than the corresponding bulk material; therefore, modalities and amount of the interactions with the bacterial surfaces are facilitated and determine a higher antibacterial activity(34).

One should also consider that a certain amount of cationic metal is released from the nanoparticles when these are dissolved in water or when they penetrate into the cells. In effect, nanoparticles have a higher antibacterial activity than the free ions of metal, whereby the antibacterial properties are attributed to both the physical properties of nanoparticles and the elution of metal ions (57). It is likely that a combined effect between the activity of the nanoparticles and free ions contributes in different ways to produce a strong antibacterial activity of broad spectrum $(8,10)$. Furthermore, the fact that bacterial resistance to elemental metal is extremely rare (58), emphasizes the presence of multiple bactericidal mechanisms that act in synergy. The metal ions bind to the protein and nucleic acid negatively charged, causing structural changes and deformations in the wall, in the membranes and in the nucleic acids of the bacterial cell. In fact, metal ions interact with a number of electron donor functional groups such as thiols, phosphates, hydroxyls, imidazoles and indoles $(10,12)$. The NPs also damage membranes and induce the release of reactive oxygen species (ROS), forming free radicals with a powerful bactericidal action (46). Metal ions or small NPs can easily enter the microbial body causing the damage of its intracellular structures. As a consequence ribosomes may be denatured with inhibition of protein synthesis, as well as translation and transcription can be blocked by the binding with the genetic material of the bacterial cell $(33,59,60)$. Protein synthesis has been shown to be altered by treatment with NPs and proteomic data have shown an accumulation of immature precursors of membrane proteins resulting in destabilization of the composition of the outer membrane (61), in Figure 1, we summarize the possible toxicity mechanisms of NPs.

The correlation between the bactericidal effect and AgNP concentrations is bacterial class dependent (22). Indeed, Pseudomonas aeruginosa and Vibrio cholera were more resistant than E. coli and Salmonella typhi, but at concentrations above $75 \mu \mathrm{g} / \mathrm{mL}$, the bacterial growth was completely abolished (50). In this perspective, Kim et al.,2007(34) studied NPs antimicrobial activity against $E$. coli and $S$. aureus showing that $E$. coli was inhibited at low concentrations, while the inhibitory effects on the growth of $S$. aureus were less marked (65). NPs have been shown to be definitely an effective antibiotic against E. coli, S. typhi, Staphylococcus epidermidis and $S$. aureus (52). Increasing scientific evidence has demonstrated that AgNP activity would depend not only on their concentration and size $(16,41)$, but also on their shape (45). In this regard, E. coli 
seems to respond better to triangular nanoparticles and is inhibited at low concentrations (46). Pal et al., 2014(35) studied the effect of nanoparticles with spherical, rod-like and triangular shapes against $E$. coli, they showed that all of them had antimicrobial activity, wihile the triangular nanoparticles being qualitatively more effective. Probably the triangular shape gives a greater positive charge to the nanoparticles, which together with the active facets on a triangular-shaped particle is able to ensure a greater activity.

It has been suggested that NPs also interfere with bacterial replication processes by adhering to their nucleic acids (41). This assumption, however, is controversial: for some authors NPs do not damage DNA (55), while according to others they intercalate into the DNA56). All factors which influence the activity of NPs(concentration, size, shape, UV radiation and the combination with various antibiotics) should be taken into consideration when preparing NPs for clinical use (20). Resistance to silver compounds as determined by bacterial plasmids and genes has been defined by molecular genetics, these findings should eliminate recent skepticism about the existence of silver-resistant bacteria. Now that the means for identifying silver resistance determinants in Enterobacteriaceae is available, similar efforts are needed with other common pathogens. The wide and uncontrolled use of silver products may result in more bacteria developing resistance(58). Notwithstanding the many conflicts in the literature regarding the effects of antibacterial NPs, it is likely that the result of a combined effect of each contributing feature, which provide a broad spectrum of antibacterial activity and decrease the probability of developing resistance (59). In Figure 2, the hypothesized bactericidal mechanisms are reported, where DNA damage through ROS is of particular interest and could be induced by NPs. In light of the decreasing effectiveness of classical antibiotics due to the emergence of biological resistance, the use of NPs in association with antibiotic drugs can be seen as an alternative for such difficult treatments(63). In fact, Singh et al.,2013(62) investigated individual and combined effects of NPs with 14 antibiotics belonging to seven classes against seven pathogenic bacteria using the disc-diffusion method. Their results showed the feasibility of the strategy, but different levels of activity increments, according to the class of antibiotic used, were observed. Aminoglycosides showed a small increase with the exception of gentamicin against Acinetobacter baumannii and kanamycin against $P$. aeruginosa (63). Considerable enhancement of the antibacterial effect was observed for amoxicillin in the presence of NPs against $P$. aeruginosa and penicillin demonstrated a 3-fold increase of efficiency against Streptococcus mutans. Vancomycin, with a 3.8-fold increase of activity against Enterobacter aerogenes, was reported to have the highest overall synergistic activity in combination with NPs compared to all other antibiotics(64). They also tested clinical derived bacterial strains, exhibiting resistance to one or more antibiotics belonging to the $\beta$-lactam class, and showed that the addition of NPs downsized MIC (minimum inhibitory concentration) into the susceptibility range, therefore, addition of NPs not only reduced MICs, but also rendered bacteria susceptible to antibiotic treatment $(66,67)$.

This is of great importance since the administration of small amounts of NPs in combination with antibiotics can reduce the required dose of antibiotics to achieve the same effect by up to 1000-fold(64). Synergistic action of NPs and antibiotics 
resulted in enhanced antibacterial effects; therefore, the simultaneous action of antibiotics and NPs can hamper the resistance development by pathogenic bacteria, also in view of the reduced amount of antibiotic administered $(62,68)$. Fayaz et $a l ., 2010$ (63) suggested that the increase in synergistic effect may be caused by the bonding reaction between antibiotic and NPs. They tested a set of antibiotics and found that the highest percentage of fold increase was obtained with ampicillin followed by kanamycin, erythromycin and chloramphenicol against all test strains. Interestingly, they realised that the percentage of fold increase in ampicillin with NPs against Gram-positive and Gramnegative bacteria were almost identical, even though inhibition of Gram-positive bacteria is generally more difficult to obtain with NPs alone. Furthermore, a different study analysed a set of clinical bacterial isolates exhibiting resistance against conventional sulphonamide (trimethoprim) andglycopeptides (vancomycin) antibiotics (64). A synergistic effect of antibiotics in conjugation with biologically synthesized NPs increased the susceptibility among the tested bacteria from $20 \%$ to $30 \%$. The combined effect of NPs and antibiotics was notably against $E$. coli, $P$. aeruginosa, $S$. aureus, K. pneumonia, Bacillus spp, and Micrococcus luteus. These results are also in line with the findings reported by Birla et al. 2009 (65) who registered increasing efficiency of antibiotics like vancomycin, gentamycin, streptomycin, ampicillin and kanamycin when used in combination with NPs against $P$. aeruginosa, $S$. aureus and $E$. coli.

Since NPs modified with different coatings such as polyethyleneimines (66), chitosan (48), glucosamine (67) and peptides (personal unpublished data)generally showed an increased antibacterial activity that has been related to the increased uptake as a consequence of a greater binding ability of nanoparticles to bacterial cells, Brown et al. (68) functionalised the surface of NPs with ampicillin (NP-AMP). They observed that NP-AMPs had increased biocidal activity compared to NPs. Their data suggested that the antimicrobial activity of functionalized NP-AMPs reside in the combined effect of the AgNP and the ampicillin carried onthe surface of the nanoparticle. The use of combination strategies for combating antibiotic resistance is slowly finding its way as a promising attempt to reduce the amount of antibiotics to be administered, therefore lowering the chances of steady resistance development. Selected studies on the antibacterial activity of NPsare summarized inTable 1.

\section{The Antibiofilm Activity of Nanoparticles}

Microorganisms growing in biofilms cause many of infections. The most common biofilm-forming bacteria associated with human infections are: E. faecalis, S. aureus, S. epidermidis, Streptococcus viridans, E. coli, K. pneumoniae, Moraxella catarrhalis, Proteus mirabilis and $P$. aeruginosa (15). Biofilms may be one of the leading causes for a shift from acute-phase diseases to chronic diseases. Most common diseases involving bacteria able to form biofilmare biliary tract infections, cystic fibrosis, dental caries, endocarditis, otitis and periodontal diseases(76).Moreover, several infections may be associated with foreign body material such as contact lens, sutures, artificial heart valves, arteriovenous shunts, catheters and orthopedic prostheses. The sites of infections may be different but the characteristics (mechanism for biofilm formation and development of resistance) of the causative agent are similar(16,17).

Biofilms are communities of 
microorganisms attached to a solid surface, these adherent cells are frequently embedded within a self-produced matrix of extracellular polymeric substance. Biofilm extracellular polymeric substance is a conglomeration composed of DNA, proteins and polysaccharides (73). The matrix is produced under the control of enzymes secreted in response to nutrient availability (74). Biofilms develop in natural aquatic systems, water pipes, on the teeth, on medical devices (15). The signals that promote biofilm rapid formation are:(i) presence of a suitable surface; (ii) increase of extracellular iron; (iii) presence of indole, polyamines, calcium and bile salts (75-77). In the initial phase of biofilm formation, bacterial attacks proliferate, forming microcolonies and attracting surrounding cells. The mature biofilm is a real microbial community that exchanges and shares products in a dynamic manner (78). In fact, cell growth, death, nutrients acquisition, the accumulation of waste products, mechanisms of motility and exopolysaccharide synthesis can affect the structure and attributes of biofilms $(77,79)$.

A biofilm formation divided into the following phases: (i) the planktonic form, in which the separated cells are floating or swimming independently in a liquid support; (ii) the aggregated state, or sessile, in which cells are closely bound and firmly attached to one another and also, usually, to a solid surface. The change in behavior is triggered by a chemical communication mechanism that differs between species. Some species, for example, can produce acylhomoserine lactones as a "rest" signal, which induces planktonic cells that surround the phenotypic variation to change into the sessile state, through a different expression of the genes of the cell. As the understanding of biofilm increases, it is becoming evident that biofilm phenotypes cannot be analysed and eventually fought using the traditional principles of bacteriology. In fact, the properties of a biofilm are similar to the properties of a polymer and not to the properties of a sum of cells. Indeed, biofilms possess elastic and viscous properties which allows the community to adhere, grow in a tridimensional structure and move inside the lumen of a catheter or a similar device.

The pathogenicity of biofilms can be summarised by the following properties: (i) attachment to solid surfaces to high density; (ii) increased metabolic efficiency of the community; (iii)evasion of host-defences; (iv) horizontal gene transfer; (v) antimicrobial resistance; (vi) detachment of microbial aggregates able to colonise other sites (16,85). Bacterial biofilms are particularly unmanageable by antibiotic treatments not only due to an increase in transmission of resistance markers within the biofilm community, but also because the extracellular matrix hampers antibiotic diffusion, because the effectiveness of antibiotics is inactivated more easily, and because metabolically inactive persistent cells survive treatment. Together these features make bacterial biofilms up to 1000 times more resistant to antibiotics than planktonic cells $(86,88)$. The antibiofilm activity of NPs has been demonstrated in a number of studies and is briefly described in the rest of the section $(89,92,100)$. One pioneering study was performed to analyse the interactions of NPs with Pseudomonas putida biofilms. The results suggested that biofilms are impacted by the treatment with NPs. The nanoparticles analyzed in the study were ofquite large dimensions (over $60 \mathrm{~nm}$ ) (80). One of the first reports on the antibiotic effect of NPs on $P$. aeruginosa and $S$. epidermidis, and their effect on biofilm formation, was produced by Kalishwaralal et al.2010.,(81). The study 
focused on two important pathogens causing keratitis and the effect of a $2 \mathrm{~h}$ of treatment with NPs at a concentration of $100 \mu \mathrm{M}$ showed that a $95 \%$ and $98 \%$ decrease of the biofilm was obtained. Therefore the authors concluded that NPs are able to induce the detachment of $P$. aeruginosa and $S$. epidermidis with rapidity and efficiency, opening clinical possibilities of alternative therapies(53).

An important feature to evaluate the real efficiency of the nanoparticles is derived from the chosen stabilization method employed. To this regard several coatings and chemicals have been reported:(i) starch was successfully employed to prepare NPs which had a disrupting effect on biofilms produced by $P$. aeruginosa and $S$. aureus (82); (ii) citrate-capped NPs of various sizes were shown to inhibit $P$. aeruginosaPAO1 biofilms (83); (iii) polyvinylpyrrolidone (PVP) showed good antibacterial activity towards $S$. aureus, E. coli, $P$. aeruginosa, Bacillus subtilis, and good fungicidal activity against various yeasts and molds (84); (iv) $\beta$-cyclodextrin is also an effective capping and stabilizing agent that reducesthe toxicity of NPs against the mammalian cell while enhancing their antibiofilm activity (85). Mohanty et al,2012(82) used a simple and environment friendly approach to form stable colloids of nontoxic NPs using starch to reduce metal nitrate to metal and simultaneously stabilize the nanoparticles in starch solution. Then they tested the effect of NPs on biofilm formation by $P$. aeruginosa and S.aureus with varying concentrations of NPs. Longer treatments $(48 \mathrm{~h})$ increased the antibiofilm efficiency to approximately $65 \%$ and $88 \%$ reduction in biofilm formation at micromolar concentrations. The ability to disrupt $P$. aeruginosa biofilm formation after treatment with the antimicrobial peptideLL-37, already known to impair biofilm formation, and NPs was also analysed and, in comparison toLL-37, treatment with NPs resulted in a 3-fold reduction of biofilm formation(90).

Multi-drug resistant (MDR) strains of $P$. aeruginosa were treated with NPs to investigate the eventual increased resistance compared to sensible strains. In the multidrug resistant strains, the inhibition rate of NPs was highest at concentration of 20 $\mu \mathrm{g} / \mathrm{mL}$ similarly to the parental strain, therefore biofilms derived from multiresistant bacteria do no show an increased resistance to metal (69). Antibiofilm action of NPs of $8.3 \mathrm{~nm}$ in diameter stabilized by hydrolyzed casein peptides on Gram-negative bacteria (E. coli, $P$. aeruginosa and Serratia proteamaculans) was investigated byRadziget al.2013(86). A strong inhibition of biofilms formation was observed. Interestingly, several $E$. coli strains with mutations in genes responsible for the repair of DNA containing oxidative lesions (mutY, mutS, mutM, mutT, nth) were also analyzed and found less resistant to NPs than wild type strains, suggesting a possible involvement of these genes in repair of AgNP-produced damages to cellular DNA. The outer membrane of Gram-negative contains water-filled channels (called porins) to allow the exchange with the environment of lowmolecular weight compounds. Porins are involved in the transport of $\mathrm{Ag}$-ions and $E$. coli bacteria expressing mutated porin proteins are less susceptible to metal ions action (87). Radzig et al.2013,(86) confirmed that $E$. coli mutant strains deficient in OmpF or OmpC porins were 48 times more resistant to NPs when compared to the wild type strain, suggesting that porins have a key role in allowing NPs to exert their antibacterial effect.

The anti-biofilm activity of metal 
nanoparticles was also demonstrated in other studies mainly focused on bacteria showing resistance to conventional antibiotics (88,89). The biofilm formation by methicillin resistant $S$. aureus (MRSA) and methicillin resistant $S$. epidermidis (MRSE) isolated from infected wounds was also analyzed by confocal laser scanning microscopy (CLSM) techniques which provided concrete evidence of the ability of NPs to block bacterial growth and to prevent the glycocalyx formation. A complete antibiofilm activity was obtained with NPs at a concentration lower than $50 \mu \mathrm{g} / \mathrm{mL}$ (88). Gurunathan et al.,2014(90) analyzed the anti- bacterial and antibiofilm activity of antibiotics or NPs, or combinations of both against $P$. aeruginosa, Shigella flexneri, $S$. aureus, and Streptococcus pneumonia. They were able to show a clear enhancing effect for ampicillin andvancomycin against either Gram-negative or Gram-positive bacteria, suggesting that combining NPs withantibiotics could be a possible alternative therapeutic strategy against bacterial infectious diseases.

Table.1 Selected Studies on the Antibacterial Activity of Metal Nanoparticles

(Sebasten Et Al,Gbj 2014 )

\begin{tabular}{|c|c|c|c|c|}
\hline Organism & Functionalization & Size $(\mathrm{nm})$ & Effect & Ref. \\
\hline $\begin{array}{c}\text { E. coli } \\
\text { S. aureus }\end{array}$ & unfunctionalized & Not declared & MIC $100 \mu g \mathrm{~mL}$ & [4] \\
\hline $\begin{array}{l}\text { E. coli } \\
\text { S. nphi } \\
\text { S. aureus }\end{array}$ & unfunctionalized & $10-15$ & $\begin{array}{l}\text { MIC } 25 \mu \mathrm{gL} \\
\mathrm{MIC} 25 \mu \mathrm{gL} \\
\text { MIC } 100 \mu \mathrm{gLL}\end{array}$ & [36] \\
\hline E. coli & unfunctionalized & 12 & $\mathrm{MIC}_{2} 10 \mu \mathrm{mL}$ & [32] \\
\hline $\begin{array}{c}\text { E. coll } \\
\text { S. aurews }\end{array}$ & Unfuctionalized & 13.5 & $\begin{array}{c}\text { MIC } 3.3-6.6 \mathrm{nM} \\
\mathrm{MIC}>33 \mathrm{nM}\end{array}$ & [34] \\
\hline P. aengemosa & unfunctionalized & $20-30$ & $\mathrm{MIC} 20 \mu \mathrm{g} \mathrm{mL}$ & [69] \\
\hline $\begin{array}{c}\text { E. coll } \\
\text { V. cholerse } \\
\text { S. oplit } \\
\text { P. acruginosa }\end{array}$ & unfunctionalized & 21 & $\mathrm{MIC} 75 \mu \mathrm{gL}$ & [33] \\
\hline $\begin{array}{l}\text { E. coli } \\
\text { S. mirems }\end{array}$ & poly(amidehydroxyurethane)-coasted & 23 & $\mathrm{MIC} 10 \mu \mathrm{mL}$ & [37] \\
\hline Bnicella abortus & unfunctionalized & $3-18$ & MIC $6-8 \mathrm{ppm}$ & {$[70]$} \\
\hline E. coli & citrate & 30 & MIC $-10 \mu \mathrm{gmL}$ & [38] \\
\hline S. aurews & unfunctionalized & 5.5 & MIC $0.2-4 \mu 2 \mathrm{~mL}$ & [71] \\
\hline E. colli & unfunctionalized & 50 & $\mathrm{MIC}_{n} 0.1 \mu 2 \mathrm{~mL}$ & [35] \\
\hline $\begin{array}{l}\text { E. coll } \\
\text { S. aureeis }\end{array}$ & unfunctionalized & $\$ 5$ & MIC $0.25 \mu g \mathrm{~mL}$ & [40] \\
\hline $\begin{array}{l}\text { V. chiolerue } \\
\text { ETEC }\end{array}$ & unfunctionalized & $88-100$ & $\begin{array}{l}\text { MIC } 1.6 \times 10^{9} \text { formL } \\
\text { MIC } 1.2 \times 10^{8} \text { for mL }\end{array}$ & [72] \\
\hline
\end{tabular}

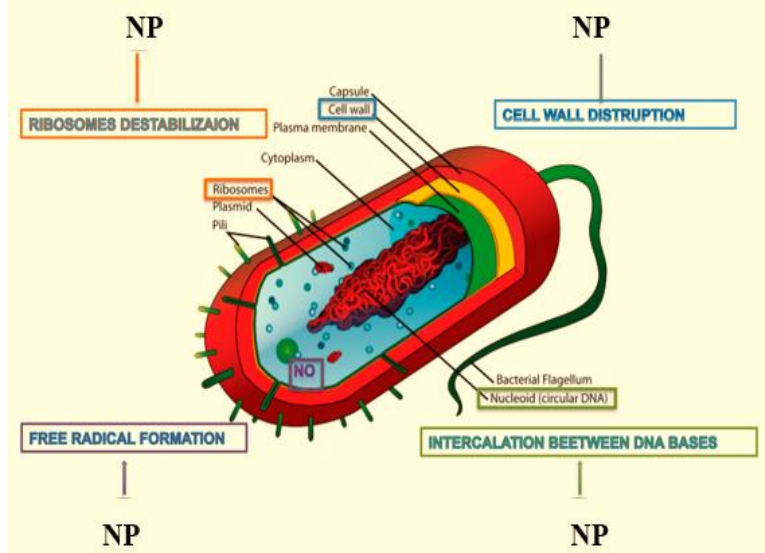

Figure.1 Mechanisms of Nps' Toxic Action (Mohammed et al., tib j 2012) 


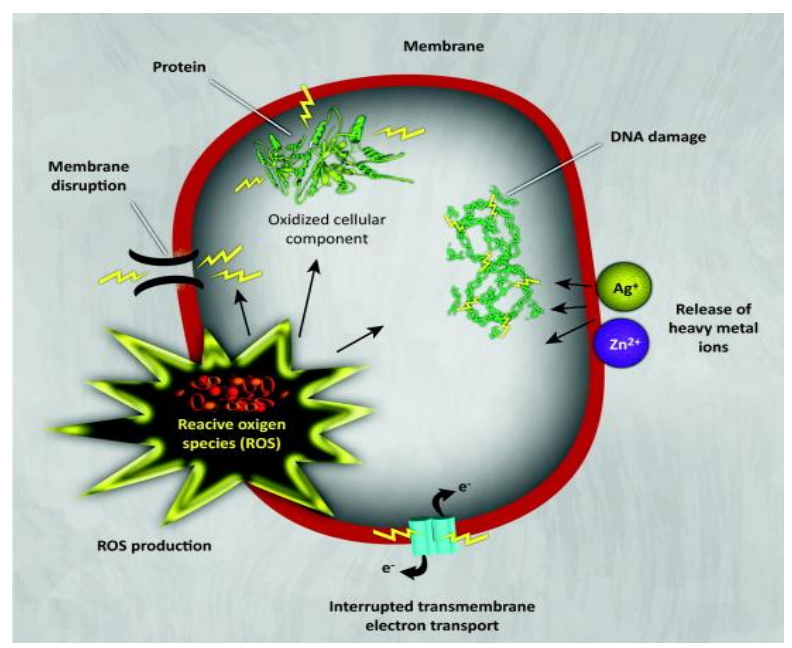

Figure.2 Mechanisms of Toxicity of Nanoparticles (nps) against Bacteria. Nps and their Ions (e.g., silver and zinc) can Produce Free Radicals, Resulting in Induction of Oxidative Stress (i.e., Reactive Oxygen species; ros). The produced Ros can Irreversibly Damage Bacteria Resulting in Bacterial Death (Trends in Biotechnology, January 2013).

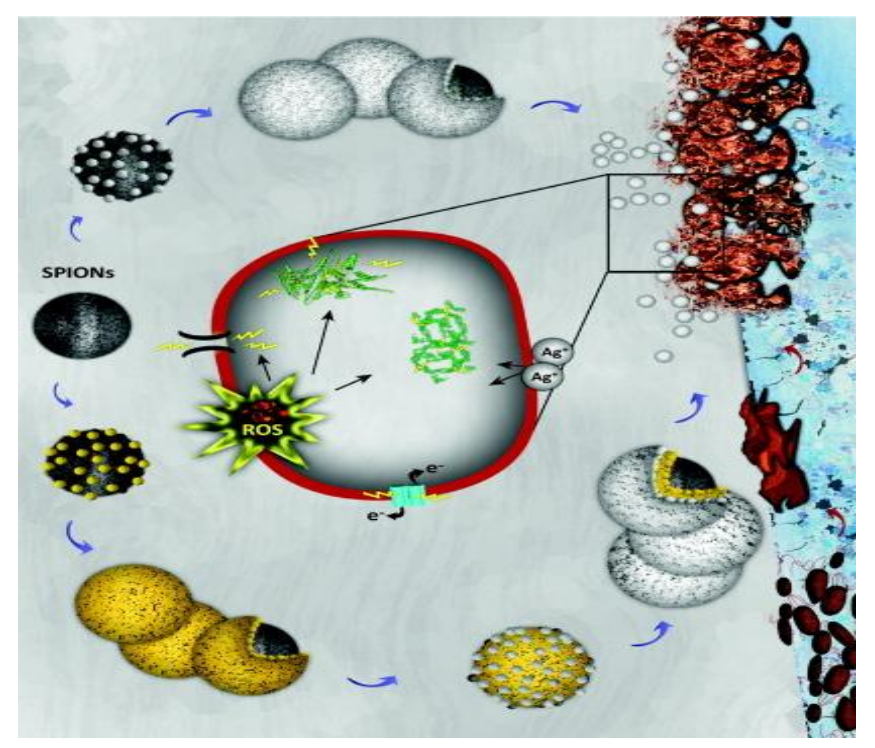

Figure.3 Schematic representation of toxicology effect of multifunctional nanoparticles (NPs) in bacterial biofilms. Monodisperse superparamagnetic iron oxide NPs (SPIONs; black spheres) are coated with silver (gray shell), gold (yellow shell), and silver ring-coated, gold-coated SPIONs; silver ring-coated SPIONs and silver ring-coated, gold-coated SPIONs have strong toxic effects on bacterial biofilms, by penetration into the biofilms. Both SPIONs cores and the intermediate gold shell have the capability to induce heat by applying alternative magnetic and laser fields, respectively; the produced heat can be used as additional means to escalate bacterial death using these NPs. The magnified section in the center illustrates the irreversible effects of NPs and their ions on the various parts of the bacteria (Trends in Biotechnology, January 2013). 
An interesting evolution of using nanoparticles against bacterial biofilms is represented by metal-coated magnetic nanoparticles, in fact, engineered multimodal nanoparticles comprising amagnetic core and a metal ring showed promising results (91). Along this line, magnetic and antibacterial properties have been exploited by creating super paramagnetic iron oxide nanoparticles (SPION)conjugated with metal to demonstrate that MRSA biofilms can be eradicated without the need of antibiotics(88).MRSA biofilms treated with $1 \mathrm{mg} / \mathrm{mL}$ of metal-conjugated SPION resulted in a consistent mass decrease $(11,53,17)$ as shown in figure 3.Moreover, SPION anti-biofilm efficacy is further improved in the presence of an external magnetic field. Metalis nowadays used on medical devices to support anti-biofilm activity. Biofilms from clinical isolates of $P$. aeruginosa were treated with gum arabic capped-metal nanoparticles (GA-NPs) showing a concentration dependent inhibition of bacterial growth and treatment of catheters with GA-NPs at50 $\mu \mathrm{g} / \mathrm{mL}$ resulted in $95 \%$ inhibition of bacterial colonization of the plastic catheter surface (88).Other authors have also shown the applications of nanometal as antibiofilms for coating catheters with positive results against both Gram-positive and Gramnegative bacteria $(92,94)$. Furthermore, no significant accumulation of metal was detected in the main organs of the test animals in which engineered catheters had been implanted (92).

Dental applications were obtained with composites containing metal nanoparticles that can act against $S$. mutans biofilm (95). Also, bone cements modified with NPs significantly reduced biofilm formation on the surface of the cement (96). Some medical devices, as well as surgical masks
(97), coated with NPs are already in clinical trials with promising results $(93,98,99)$. Furthermore, recent studies suggest the use of wound dressings treated with NPs to prevent or reduce microbial growth in wounds and to improve the outcomes of healing (100). A bioactive chitosan hydrogel membrane including NPs showed a synergistic activity of chitosan and NPs to reduce the growth of $S$. aureus, E. coli, $S$. epidermidis, $P$. aeruginosa strains and to disrupt mature biofilms (101).

In conclusion, antibacterial activities of NPs depend on two main factors:(i) physicochemical properties of NPs and (ii) type of bacteria, it is now clear that NPs possess a strong antibacterial activity highlighted by several studies. NPs have the ability to interact with various microorganisms (such as bacteria) and also impact both the growth and mature bacterial biofilms, and therefore, could be used as broad spectrum antimicrobials to control infection. The antibacterial effect appears to be conferred by their ultra small size and increased surface area, through which they destroy the membrane, cross the body of the microbe and create intracellular damage. Due to the structural difference in the composition of the cell walls ofGrampositive and Gram-negative NPs have significantly less effect on the growth of Gram-positive bacteria, the Gram-negative bacteria have a layer of lipopolysaccharides on the outside, and present below a thin (7 to 8 nanometers) layer of peptidoglycan. Although lipopolysaccharides are composed of lipids covalently bound to polysaccharides, there is a lack of rigidity of the overall structural envelope. The negative charges on the lipopolysaccharides are attracted to the weak positive charge of NPs, on the other hand, the cell wall of Grampositive bacteria is mainly composed of a thick layer(20 to 80 nanometers) of 
peptidoglycan consisting of linear polysaccharidic chains cross-linked by short peptides to form a three-dimensional rigid structure. The stiffness and the extensive cross-linking not only reduce the bacterial cell wall anchoring sites for NPs but also render the wall itself more difficult to penetrate.

However, the same features that make NPs attractive, at the same time raise important issues such as the toxicity and environmental safety. NPs' antibacterial effects have been described in detail, but their mechanism of action is still unclear. A multifaceted mechanism against microorganisms seem to be due to nanoparticle interactions with the bacterial surfaces, as well as to their particular structure. Defining NPs' mechanism of action is, nowadays, a priority for biomedical research and more research on the bioactivity and biocompatibility of NPs is necessary. Understanding the kinetics of dissolution that lead to transformations of NPs in the presence of specific inorganic ligands is crucial to determining their antimicrobial activity and overall toxicity in the environment. Metal ions (Ag+), released by NPs, are likely to interact with chloride $(\mathrm{Cl}-)$ which is often present in bacterial growth media and exhibits a strong affinity for oxidized metal. High concentrations of chloride ions in the routinely used media can cause precipitation of $\mathrm{Ag}$ ions as $\mathrm{AgCl}$, thus masking the contribution of dissolved metal to NPs antibacterial effect. This consideration should influence the choice of the medium to be used when evaluating antimicrobial effects and more studies are needed to investigate the contribution of $\mathrm{AgCl}$ to the observed antibacterial activity of NPs.

The studies on the combined use of NPs with other antimicrobial agents can help reduce the problem of toxicity and to avoid the potential for development of resistance, and above all strongly enhance the microbicidal effect. The broad spectrum of bioactivity of NPs makes them promising agents not only to fight infections, but in many other biomedical areas.

\section{References}

1.Witte, W ; International dissemination of antibiotic resistantstrains of bacterial pathogens. Infect. Genet. E2004,4, 187-191

2.Klevens, R.M.; Morrison, M.A.; Nadle, J.; Petit, S.; Gershman, K.; Ray, S.; Harrison, L.H.;Lynfield, R.; Dumyati, G.; Townes, J.M.; et al. Invasive methicillin-resistant Staphylococcusaureus infections in the United States. JAMA 2007, 298, 17631771.

3.D'Costa, V.M.; King, C.E.; Kalan, L.; Morar, M.; Sung, W.W.; Schwarz, C.; Froese, D.; Zazula, G.;Calmels, F.; Debruyne, R.; et al. Antibiotic resistance is ancient. Nature 2011, 477, 457-461.

4.Dos Santos, C.A.; Seckler, M.M.; Ingle, A.P.; Gupta, I.; Galdiero, S.; Galdiero, M.; Gade, A.; Rai, M.Metal nanoparticles: Therapeutical uses, toxicity, and safety issues. J. Pharm. Sci. 2014, 103,1931-1944.

5.Seppala, H.; Klaukka, T.; Vuopio-Varkila, J.; Muotiala, A.; Helenius, H.; Lager, K.; Huovinen, P.The effect of changes in the consumption of macrolide antibiotics on erythromycin resistance in group A streptococci in Finland. Finnish Study Group for Antimicrobial Resistance. $N$. Engl. J. Med.1997, 337, 441-446.

6.Andersson, D.I.; Hughes, D. Antibiotic resistance and its cost: Is it possible to reverse resistance Nat. Rev. Microbiol. 2010, 8, 260-271.

7.Long, K.S.; Vester, B. Resistance to linezolid caused by modifications at its binding site on the ribosome. Antimicrob. Agents Chemother. 2012, 56, 603-612.

8.Cassir, N.; Rolain, J.M.; Brouqui, P. A new strategy to fight antimicrobial resistance: The revival of old antibiotics. Front. Microbiol. 2014, 5, 551. 
9.Chen, X.; Schluesener, H.J. Nanometal: A nanoproduct in medical application. Toxicol. Lett. 2008,176, 1-12.

10.Rai, M.K.; Deshmukh, S.D.; Ingle, A.P.; Gade, A.K. Metal nanoparticles: The powerful nanoweaponagainst multidrugresistant bacteria. J. Appl. Microbiol. 2012, 112, 841-852.

11.Jana, S.; Pal, T. Synthesis, characterization and catalytic application of metalnanoshell coated functionalized polystyrene beads. $J$. Nanosci. Nanotechnol. 2007, 7, 2151-2156.

12. Stiufiuc, R.; Iacovita, C.; Lucaciu, C.M.; Stiufiuc, G.; Dutu, A.G.; Braescu, C.; Leopold, N. SERSactivemetal colloids prepared by reduction of metal nitrate with short-chain polyethylene glycol.NanoscaleRes. Lett.2013, 8, doi:10.1186/1556-276X-8-47.Molecules 2015, 208869

13.Szmacinski, H.; Lakowicz, J.R.; Catchmark, J.M.; Eid, K.; Anderson, J.P.; Middendorf, L.Correlation between scattering properties of metal particle arrays and fluorescence enhancement. Appl. Spectrosc. 2008, 62, 733-738.

14.Lazar, V. Quorum sensing in biofilms-How to destroy the bacterial citadels or their cohesion/power Anaerobe 2011, 17, 280285.

15.Donlan, R.M.; Costerton, J.W. Biofilms: Survival mechanisms of clinically relevant microorganisms.Clin. Microbiol. Rev. 2002, 15, 167-193.

16.Taraszkiewicz, A.; Fila, G.; Grinholc, M.; Nakonieczna, J. Innovative strategies to overcome biofilm resistance. Biomed. Res. Int. 2013, 150653.

17.Biel, M.A.; Sievert, C.; Usacheva, M.; Teichert, M.; Balcom, J. Antimicrobial photodynamictherapy treatment of chronic recurrent sinusitis biofilms. Int. Forum Allergy Rhinol. 2011, 1,329-334.

18.Rai, M.; Deshmukh, S.D.; Ingle, A.P.; Gupta, I.R.; Galdiero, M.; Galdiero, S. Metal nanoparticles:The protective nanoshield against virus infection. Crit. Rev. Microbiol. 2014, 1-11.

19.Rai, M.; Kon, K.; Ingle, A.; Duran, N.; Galdiero, S.; Galdiero, M. Broad-spectrum bioactivities ofmetal nanoparticles: The emerging trends and future prospects. Appl. Microbiol. Biotechnol. 2014,98, 19511961.

20.Galdiero, S.; Falanga, A.; Vitiello, M.; Cantisani, M.; Marra, V.; Galdiero, M. Metal nanoparticlesas potential antiviral agents. Molecules 2011, 16, 8894-8918.

21.Mijnendonckx, K.; Leys, N.; Mahillon, J.; Metal, S.; Van Houdt, R. Antimicrobial metal: Uses, toxicity and potential for resistance. Biometals2013, 26, 609-621.

22.Chernousova, S.; Epple, M. Metal as antibacterial agent: Ion, nanoparticle, and metal. Angew. Chem. Int. Ed. Engl. 2013, 52, 1636-1653.

23.Sweet, M.J.; Chesser, A.; Singleton, I. Review: Metal-based nanoparticles; size, function, and areasfor advancement in applied microbiology. Adv. Appl. Microbiol. 2012, 80, 113-142.

24.Sweet, M.J.; Singleton, I. Metal nanoparticles: A microbial perspective. $A d v$. Appl. Microbiol.2011, 77, 115-133.

25.Lara, H.H.; Garza-Trevino, E.N.; IxtepanTurrent, L.; Singh, D.K. Metal nanoparticles are broad-spectrum bactericidal and virucidal compounds. $J$. Nanobiotechnol. 2011, 9, 30.

26.Salunke, G.R.; Ghosh, S.; Santosh Kumar, R.J.; Khade, S.; Vashisth, P.; Kale, T.; Chopade, S.; Pruthi, V.; Kundu, G.; Bellare, J.R.; et al. Rapid efficient synthesis and characterization of metal, gold, and bimetallic nanoparticles from the medicinal plant Plumbago zeylanica and their applicationin biofilm control. Int. J. Nanomedicine 2014, 9, 2635-2653.

27.Lysakowska, M.E.; Ciebiada-Adamiec, A.; Klimek, L.; Sienkiewicz, M. The activity of metal nanoparticles (Axonnite) on clinical and environmental strains of Acinetobacter spp. Burns 2015,41, 364-371.

28.Manjumeena, R.; Duraibabu, D.; Sudha, J.; Kalaichelvan, P.T. Biogenic nanometal incorporated reverse osmosis membrane for antibacterial and antifungal activities against selected pathogenic strains: An enhanced eco-friendly water disinfection approach. J. Environ. Sci. Health A ToxicHazard. Subst. Environ. Eng. 2014, 49, 1125-1133. 
29. Vazquez-Munoz, R.; Avalos-Borja, M.; Castro-Longoria, E. Ultrastructural analysis of Candida albicans when exposed to metal nanoparticles. PLoS ONE 2014, 9, e108876.Molecules 2015, 208870

30.Junqueira, J.C.; Jorge, A.O.; Barbosa, J.O.; Rossoni, R.D.; Vilela, S.F.; Costa, A.C.; Primo, F.L.;Goncalves, J.M.; Tedesco, A.C.; Suleiman, J.M. Photodynamic inactivation of biofilms formed byCandida spp., Trichosporon mucoides, and Kodamaeao hmeri by cationic nanoemulsion of zinc2,9,16,23-tetrakis (phenylthio)-29H,31H-phthalocyanine (ZnPc). Lasers Med. Sci. 2012, 27, 12051212.

31.Wang, C.; Huang, X.; Deng, W.; Chang, C.; Hang, R.; Tang, B. A nano-metal composite based onthe ion-exchange response for the intelligent antibacterial applications. Mater. Sci. Eng. C Mater.Biol. Appl. 2014, 41, 134-141.

32.Sondi, I.; Salopek-Sondi, B. Metal nanoparticles as antimicrobial agent: A case study on E. coli asa model for Gramnegative bacteria. J. Colloid Interface Sci. 2004, 275, 177-182.

33.Morones, J.R.; Elechiguerra, J.L.; Camacho, A.; Holt, K.; Kouri, J.B.; Ramirez, J.T.; Yacaman, M.J.The bactericidal effect of metal nanoparticles. Nanotechnology 2005, 16, 2346-2353.

34. Kim, J.S.; Kuk, E.; Yu, K.N.; Kim, J.H.; Park, S.J.; Lee, H.J.; Kim, S.H.; Park, Y.K.; Park, Y.H.; Hwang, C.Y.; et al. Antimicrobial effects of metal nanoparticles. Nanomedicine 2007, 3, 95101.

35.Pal, S.; Tak, Y.K.; Song, J.M. Does the antibacterial activity of metal nanoparticles depend on theshape of the nanoparticle? A study of the Gram-negative bacterium Escherichia coli. Appl. Environ. Microbiol. 2007, 73, 1712-1720.

36.Shrivastava, S.; Bera, T.; Singh, S.K.; Singh, G.; Ramachandrarao, P.; Dash, D. Characterization of antiplatelet properties of metal nanoparticles. ACS Nano 2009, 3, 1357-1364.

37.Stefan, M.; Hritcu, L.; Mihasan, M.; Pricop, D.; Gostin, I.; Olariu, R.I.; Dunca, S.;
Melnig, V. Enhanced antibacterial effect of metal nanoparticles obtained by electrochemical synthesis inpoly (amidehydroxyurethane) media. J. Mater. Sci. Mater. Med. 2011, 22, 789-796.

38.Zhou, Y.; Kong, Y.; Kundu, S.; Cirillo, J.D.; Liang, H. Antibacterial activities of gold and metal nanoparticles against Escherichia coli and bacillus Calmette-Guerin. $J$. Nanobiotechnol. 2012, 10, doi:10.1186/1477-3155-10-19.

39. Kumar, C.G.; Sujitha, P. Green synthesis of Kocuran-functionalized metalglyco nanoparticles foruse as antibiofilm coatings on silicone urethral catheters. Nanotechnology 2014, 25. doi:10.1088/0957-4484/25/32/325101.

40.Paredes, D.; Ortiz, C.; Torres, R. Synthesis, characterization, and evaluation of antibacterial effect of $\mathrm{Ag}$ nanoparticles against Escherichia coli O157:H7 and methicillin-resistant Staphylococcus aureus (MRSA). Int. J. Nanomedicine 2014, 9, 1717-1729.

41.Naraginti, S.; Sivakumar, A. Eco-friendly synthesis of metal and gold nanoparticles with enhanced bactericidal activity and study of metal catalyzed reduction of 4nitrophenol. Spectrochim. ActaAMol. Biomol. Spectrosc. 2014, 128, 357-362.

42.Kumar, D.A.; Palanichamy, V.; Roopan, S.M. Green synthesis of metal nanoparticles using Alternanthera dentata leaf extract at room temperature and their antimicrobial activity. Spectrochim. ActaA Mol. Biomol. Spectrosc. 2014, 127, 168-171.

43.Muhsin, T.M.; Hachim, A.K. Mycosynthesis and characterization of metal nanoparticles and their activity against some human pathogenic bacteria. World J. Microbiol. Biotechnol. 2014, 30,2081-2090.

44.Dhas, S.P.; John, S.P.; Mukherjee, A.; Chandrasekaran, N. Autocatalytic growth of biofunctionalized antibacterial metal nanoparticles. Biotechnol. Appl. Biochem. 2014, 61, 322-332.Molecules 2015, 20 8871

45.Meire, M.A.; Coenye, T.; Nelis, H.J.; De Moor, R.J. Evaluation of Nd:YAG and Er:YAG irradiation, antibacterial photodynamic therapy and sodium 
hypochlorite treatment on Enterococcus faecalis biofilms. Int. Endod. J. 2012, 45, 482-491.

46.Wu, D.; Fan, W.; Kishen, A.; Gutmann, J.L.; Fan, B. Evaluation of the antibacterial efficacy of metal nanoparticles against Enterococcus faecalis biofilm. J. Endod. 2014, 40, 285-290.

47.Tamayo, L.A.; Zapata, P.A.; Vejar, N.D.; Azocar, M.I.; Gulppi, M.A.; Zhou, X.; Thompson, G.E.; Rabagliati, F.M.; Paez, M.A. Release of metal and copper nanoparticles from polyethylene nanocomposites and their penetration into Listeria monocytogenes. Mater. Sci. Eng. C Mater. Biol. Appl. 2014, 40, 24-31.

48.Wei, D.; Sun, W.; Qian, W.; Ye, Y.; Ma, X. The synthesis of chitosan-based metal nanoparticles and their antibacterial activity. Carbohydr. Res. 2009, 344, 23752382.

49.Collins, T.L.; Markus, E.A.; Hassett, D.J.; Robinson, J.B. The effect of a cationic porphyrin on Pseudomonas aeruginosa biofilms. Curr. Microbiol. 2010, 61, 411416.

50.Zhang, M.; Zhang, K.; De Gusseme, B.; Verstraete, W.; Field, R. The antibacterial and anti-biofouling performance of biogenic metal nanoparticles by Lactobacillus fermentum. Biofouling 2014, 30, 347-357.

51.Shameli, K.; Ahmad, M.B.; Jazayeri, S.D.; Shabanzadeh, P.; Sangpour, P.; Jahangirian, H.; Gharayebi, Y. Investigation of antibacterial properties metal nanoparticles prepared via green method. Chem. Cent. J. 2012, 6, doi:10.1186/1752-153X-6-73.

52.Jain, J.; Arora, S.; Rajwade, J.M.; Omray, P.; Khandelwal, S.; Paknikar, K.M. Metal nanoparticles in therapeutics: Development of an antimicrobial gel formulation for topical use. Mol. Pharm. 2009,6, 13881401.

53. Periasamy, S.; Joo, H.S.; Duong, A.C.; Bach, T.H.; Tan, V.Y.; Chatterjee, S.S.; Cheung, G.Y.; Otto, M. How Staphylococcus aureus biofilms develop their characteristic structure. Proc. Natl.Acad. Sci. USA 2012, 109, 1281-1286.

54.Rolim, J.P.; de-Melo, M.A.; Guedes, S.F.; Albuquerque-Filho, F.B.; de Souza, J.R.;
Nogueira, N.A.;Zanin, I.C.; Rodrigues, L.K. The antimicrobial activity of photodynamic therapy againstStreptococcus mutansusing different photosensitizers. J. Photochem. Photobiol. B 2012, 106,40-46.

55.Hashimoto, M.C.; Prates, R.A.; Kato, I.T.; Nunez, S.C.; Courrol, L.C.; Ribeiro, M.S. Antimicrobial photodynamic therapy on drug-resistant Pseudomonas aeruginosainduced infection. An in vivostudy. Photochem. Photobiol. 2012, 88, 590-595.

56.Lu, Z.; Dai, T.; Huang, L.; Kurup, D.B.; Tegos, G.P.; Jahnke, A.; Wharton, T.; Hamblin, M.R. Photodynamic therapy with a cationic functionalized fullerene rescues mice from fatal woundinfections. Nanomedicine 2010, 5, 1525-1533.

57.Choi, O.; Hu, Z. Size dependent and reactive oxygen species related nanometal toxicity tonitrifying bacteria. Environ. Sci. Technol. 2008, 42, 4583-4588.

58.Metal, S. Bacterial metal resistance: Molecular biology and uses and misuses of metal compounds. FEMS Microbiol. Rev. 2003, 27, 341-353.

59.Jung, W.K.; Koo, H.C.; Kim, K.W.; Shin, S.; Kim, S.H.; Park, Y.H. Antibacterial activity and mechanism of action of the metal ion in Staphylococcus aureus and Escherichia coli. Appl. Environ. Microbiol. 2008, 74, 2171-2178. Molecules 2015, 208872

60.Bury, N.R.; Wood, C.M. Mechanism of branchial apical metal uptake by rainbow trout is via theproton-coupled $\mathrm{Na}(+)$ channel. Am. J. Physiol. 1999, 277, R1385R1391.

61.Mirzajani, F.; Ghassempour, A.; Aliahmadi, A.; Esmaeili, M.A. Antibacterial effect of metal nanoparticles on Staphylococcus aureus. Res. Microbiol. 2011, 162, 542549.

62.Singh, R.; Wagh, P.; Wadhwani, S.; Gaidhani, S.; Kumbhar, A.; Bellare, J.; Chopade, B.A.Synthesis, optimization, and characterization of metal nanoparticles from Acinetobacter calcoaceticus and their enhanced antibacterial activity when combined with antibiotics. Int. J.Nanomedicine 2013, 8, 4277-4290.

63.Fayaz, A.M.; Balaji, K.; Girilal, M.; Yadav, R.; Kalaichelvan, P.T.; Venketesan, R. 
Biogenic synthesis of metal nanoparticles and their synergistic effect with antibiotics: A study against Gram-positive and Gramnegative bacteria. Nanomedicine 2010, 6, 103-109.

64.Naqvi, S.Z.; Kiran, U.; Ali, M.I.; Jamal, A.; Hameed, A.; Ahmed, S.; Ali, N. Combined efficacy of biologically synthesized metal nanoparticles and different antibiotics against multidrug-resistant bacteria. Int. J. Nanomedicine 2013, 8, 3187-3195.

65.Birla, S.S.; Tiwari, V.V.; Gade, A.K.; Ingle, A.P.; Yadav, A.P.; Rai, M.K. Fabrication of metal nanoparticles by Phomaglomerataand its combined effect against Escherichia coli, Pseudomonasaeruginosa and Staphylococcus aureus. Lett. Appl. Microbiol. 2009, 48, 173-179.

66.Aymonier, C.; Schlotterbeck, U.; Antonietti, L.; Zacharias, P.; Thomann, R.; Tiller, J.C.; Mecking, S.Hybrids of metal nanoparticles with amphiphilic hyperbranched macromolecules exhibiting antimicrobial properties. Chem. Commun. 2002, 30183019.

67.Veerapandian, M.; Lim, S.K.; Nam, H.M.; Kuppannan, G.; Yun, K.S. Glucosaminefunctionalized metal glyconanoparticles: Characterization and antibacterial activity. Anal. Bioanal. Chem. 2010, 398,867-876.

68.Brown, A.N.; Smith, K.; Samuels, T.A.; Lu, J.; Obare, S.O.; Scott, M.E. Nanoparticles functionalized with ampicillin destroy multiple-antibiotic-resistant isolates of Pseudomonas aeruginosa and Enterobacter aerogenes and methicillin-resistant Staphylococcus aureus. Appl. Environ. Microbiol.2012, 78, 2768-2774.

69.Palanisamy, N.K.; Ferina, N.; Amirulhusni, A.N.; Mohd-Zain, Z.; Hussaini, J.; Ping, L.J.; Durairaj, R. Antibiofilm properties of chemically synthesized metal nanoparticles found against Pseudomonas aeruginosa. J. Nanobiotechnol. 2014, 12, doi:10.1186/1477-3155-12-2.

70.Alizadeh, H.; Salouti, M.; Shapouri, R. Bactericidal Effect of Metal Nanoparticles on Intramacrophage Brucella abortus544. Jundishapur J. Microbiol. 2014, 7, e9039.

71.Krychowiak, M.; Grinholc, M.; Banasiuk, R.; Krauze-Baranowska, M.; Glod, D.; Kawiak,
A.; Krolicka, A. Combination of metal nanoparticles and Droserabinata extract as a possible alternative for antibiotic treatment of burn wound infections caused by resistant Staphylococcus aureus. PLoS ONE 2014, 9, e115727.

72.Salem, W.; Leitner, D.R.; Zingl, F.G.; Schratter, G.; Prassl, R.; Goessler, W.; Reidl, J.; Schild, S.Antibacterial activity of metal and zinc nanoparticles against Vibrio cholera and enterotoxic Escherichia coli. Int. J. Med. Microbiol. 2015, 305, 8595.73. Flemming, H.C.; Wingender, J. The biofilm matrix. Nat. Rev. Microbiol. 2010, 8, 623-633.

74.Donlan, R.M. Biofilms: Microbial life on surfaces. Emerg. Infect. Dis. 2002, 8, 881890. Molecules 2015, 208873

75.Di Martino, P.; Cafferini, N.; Joly, B.; Darfeuille-Michaud, A. Klebsiella pneumoniae type 3 pilifacilitate adherence and biofilm formation on abiotic surfaces. Res. Microbiol. 2003, 154, 9-16.

76.Patel, C.N.; Wortham, B.W.; Lines, J.L.; Fetherston, J.D.; Perry, R.D.; Oliveira, M.A. Polyaminesare essential for the formation of plague biofilm. J. Bacteriol. 2006, 188, 2355-2363.

77.Karatan, E.; Watnick, P. Signals, regulatory networks, and materials that build and break bacterial biofilms. Microbiol. Mol. Biol. Rev. 2009, 73, 310-347.

78.Kostakioti, M.; Hadjifrangiskou, M.; Hultgren, S.J. Bacterial biofilms: Development, dispersal, and therapeutic strategies in the dawn of the post antibiotic era. Cold Spring Harb. Perspect. Med.2013, 3, a010306.

79.Haussler, S.; Fuqua, C. Biofilms 2012: New discoveries and significant wrinkles in a dynamic field.J. Bacteriol. 2013, 195, 2947-2958.

80.Fabrega, J.; Renshaw, J.C.; Lead, J.R. Interactions of metal nanoparticles with Pseudomonasputida biofilms. Environ. Sci. Technol. 2009, 43, 9004-9009.

81.Kalishwaralal, K.; BarathManiKanth, S.; Pandian, S.R.; Deepak, V.; Gurunathan, S. Metal nanoparticles impede the biofilm formation by Pseudomonas aeruginosa and Staphylococcus epidermidis. Colloids Surf. 
B Biointerfaces2010, 79, 340-344.

82.Mohanty, S.; Mishra, S.; Jena, P.; Jacob, B.; Sarkar, B.; Sonawane, A. An investigation on the antibacterial, cytotoxic, and antibiofilm efficacy of starch-stabilized metal nanoparticles. Nanomedicine 2012, 8, 916-924.

83.Habash, M.B.; Park, A.J.; Vis, E.C.; Harris, R.J.; Khursigara, C.M. Synergy of metal nanoparticles and aztreonam against Pseudomonas aeruginosa PAO1 biofilms. Antimicrob. Agents Chemother.2014, 58, 5818-5830.

84.Bryaskova, R.; Pencheva, D.; Nikolov, S.; Kantardjiev, T. Synthesis and comparative study on the antimicrobial activity of hybrid materials based on metal nanoparticles (NPs) stabilized by polyvinylpyrrolidone (PVP). J. Chem. Biol. 2011, 4, 185-191.

85.Jaiswal, S.; Bhattacharya, K.; McHale, P.; Duffy, B. Dual effects of beta-cyclodextrinstabilised metal nanoparticles: Enhanced biofilm inhibition and reduced cytotoxicity. J. Mater. Sci.Mater. Med. 2015, 26, 5367.

86.Radzig, M.A.; Nadtochenko, V.A.; Koksharova, O.A.; Kiwi, J.; Lipasova, V.A.; Khmel, I.A. Antibacterial effects of metal nanoparticles on Gram-negative bacteria: Influence on the growth and biofilms formation, mechanisms of action. Colloids Surf. B Biointerfaces2013, 102, 300-306.

87.Li, X.Z.; Nikaido, H.; Williams, K.E. Metalresistant mutants of Escherichia coli display active efflux of $\mathrm{Ag}+$ and are deficient in porins. J. Bacteriol. 1997, 179, 6127-6132.

88.Ansari, M.A.; Khan, H.M.; Khan, A.A.; Cameotra, S.S.; Alzohairy, M.A. Antibiofilm efficacy ofmetal nanoparticles against MRSA and MRSE isolated from wounds in a tertiary care hospital. Indian J. Med. Microbiol. 2015, 33, 101-109.

89.Ansari, M.A.; Khan, H.M.; Khan, A.A.; Cameotra, S.S.; Saquib, Q.; Musarrat, J. Gum Arabic capped-metal nanoparticles inhibit biofilm formation by multi-drug resistant strains of Pseudomonas aeruginosa. J. Basic Microbiol. 2014, 54, 688-699.

90.Gurunathan, S.; Han, J.W.; Kwon, D.N.; Kim, J.H. Enhanced antibacterial and anti- biofilm activities of metal nanoparticles against Gram-negative and Gram-positive bacteria. Nanoscale Res.Lett. 2014, 9, doi:10.1186/1556-276X-9-373.Molecules 2015, 208874

91.Mahmoudi, M.;Serpooshan, V. Metal-coated engineered magnetic nanoparticles are promising forthe success in the fight against antibacterial resistance threat. ACS Nano 2012, 6, 2656-2664.

92.Roe, D.; Karandikar, B.; Bonn-Savage, N.; Gibbins, B.; Roullet, J.B. Antimicrobial surface functionalization of plastic catheters by metal nanoparticles. J. Antimicrob. Chemother. 2008, 61, 869-876.

93.Stevens, K.N.; Croes, S.; Boersma, R.S.; Stobberingh, E.E.; van der Marel, C.; van der Veen, F.H.; Knetsch, M.L.; Koole, L.H. Hydrophilic surface coatings with embedded biocidal metal nanoparticles and sodium heparin for central venous catheters. Bioaterials 2011, 32, 1264-1269.

94.Zhang, G.; Zhao, X.; Chen, D. Dual bonding between $\mathrm{H} 2 \mathrm{O} / \mathrm{H} 2 \mathrm{~S}$ and $\mathrm{AgCl} / \mathrm{CuCl}: \mathrm{Cu} / \mathrm{Ag}$ bond, sister bond to $\mathrm{Au}$ bond. J. Phys. Chem. A 2013, 117, 10944-10950.

95.Cheng, L.; Zhang, K.; Weir, M.D.; Liu, H.; Zhou, X.; Xu, H.H. Effects of antibacterial primers with quaternary ammonium and nano-metal on Streptococcus mutans impregnated in human dentin blocks. Dent. Mater. 2013, 29, 462-472.

96.Slane, J.; Vivanco, J.; Rose, W.; Ploeg, H.L.; Squire, M. Mechanical, material, and antimicrobial properties of acrylic bone cement impregnated with metal nanoparticles. Mater. Sci. Eng. C Mater.Biol. Appl. 2015, 48, 188-196.

97.Li, Y.; Leung, P.; Yao, L.; Song, Q.W.; Newton, E. Antimicrobial effect of surgical masks coated with nanoparticles. J. Hosp. Infect. 2006, 62, 58-63.

98.Lackner, P.; Beer, R.; Broessner, G.; Helbok, R.; Galiano, K.; Pleifer, C.; Pfausler, B.; Brenneis, C.;Huck, C.; Engelhardt, K.; et al. Efficacy of metal nanoparticlesimpregnated external ventriculardrain catheters in patients with acute occlusive hydrocephalus. Neurocritical Care 2008, 8,360-365. 
99.Sacco, P.; Travan, A.; Borgogna, M.; Paoletti, S.; Marsich, E. Metal-containing antimicrobial membrane based on chitosanTPP hydrogel for the treatment of wounds. J. Mater. Sci. Mater. Med. 2015, 26, doi:10.1007/s 10856-015-5474-7.

100.Velazquez-Velazquez, J.L.; Santos-Flores, A.; Araujo-Melendez, J.; Sanchez-Sanchez, R.;Velasquillo, C.; Gonzalez, C.; MartinezCastanon, G.; Martinez-Gutierrez, F. Anti- biofilm and cytotoxicity activity of impregnated dressings with metal nanoparticles. Mater. Sci. Eng. C MaterBiol. Appl. 2015, 49, 604-611.

101.Gravante, G.; Montone, A. A retrospective analysis of ambulatory burn patients: Focus on wound dressings and healing times. Ann. R. Coll. Surg. Engl. 2010, 92, 118-123.

\section{How to cite this article:}

Eman Mohammed Halawani. 2016. Nanomedicine opened new horizons for metal nanoparticles to treat multi-drug resistant organisms. Int.J.Curr.Microbiol.App.Sci. 5(2): 397414. doi: http://dx.doi.org/10.20546/ijcmas.2016.502.045 